\title{
Application of Wireless Measurement While Drilling Technology in In- situ Leaching Uranium, Xinjiang, NW China
}

\author{
Du Zhi-ming, Liu Zheng-bang, Li Po \\ Beijing Research Institute of Chemical Engineering and Metallurgy, CNNC \\ 145 jiukeshu,Tongzhou District, Beijing, China \\ dzm126@126.com; lzbang2002@163.com; libo18@126.com
}

\begin{abstract}
In the process of in-situ leaching drilling construction, the center line of borehole deviates from the design axis for various reasons, resulting in low drilling rate, long construction period, high drilling cost, and even failing to meet the production design requirements, affecting the later leaching efficiency. The position of bit in drilling process can be monitored in real time by using wireless measurement while drilling technology. Wireless measurement while drilling is first used in in-situ leaching uranium drilling construction, and there are some problems such as the instrument does not produce pulse signals. In view of the existing problems, this paper analyses and discusses the methods to solve these problems, and provides technical support and guarantee for in-situ leaching drilling construction to reduce costs and increase efficiency.
\end{abstract}

Keywords: Acid in-situ leaching, Measurement while drilling, Pulse signal.

\section{Introduction}

In the in-situ leaching uranium mining project, technological drilling is the only way to connect with the ore bed [1-2]. The deviation of drilling hole is very important for in-situ leaching production. Because of the high density of in-situ leaching technology, the distance between holes is generally 20-40 M. Once the holes deviate from the design position, the movement path and leaching streamline of leaching solution will change greatly, resulting in the increase of "dead angle of leaching" and the imbalance of leaching intensity [3], which will lead to the reduction of production capacity of in-situ leaching mines. And the decline of uranium recovery.

The deviation data of 161 process boreholes (average hole depth is about $450 \mathrm{~m}$ ) in a block of a uranium deposit in Xinjiang were collected randomly for analysis and statistics. As shown in Table 1, as high as $6.8 \%$ of boreholes are scrapped due to excessive offset.

Table 1: Statistical table of borehole offset and number of boreholes.

\begin{tabular}{cc}
\hline deviation & hole/number \\
\hline$<2 \mathrm{~m}$ & 37 \\
$2 \sim 4 \mathrm{~m}$ & 55 \\
$4 \sim 6 \mathrm{~m}$ & 37 \\
$6 \sim 7 \mathrm{~m}$ & 21 \\
$>7 \mathrm{~m}$ & 11
\end{tabular}

Note: The boreholes with deviation greater than $7 \mathrm{~m}$ are unqualified or available, accounting for $6.8 \%$ of the total boreholes.

The development of deep seam is the inevitable trend of in-situ leaching in the future. The geological structure of deep stratum is relatively complex, the ground stress is large, and the temperature is high. Under the condition of certain permeability of ore-bearing aquifer, the spacing of drilling holes in in-situ leaching mining will not increase significantly. Mining and design departments have realized the importance of hole deviation and rectification, so they regard hole deviation as one of the important quality requirements for acceptance, even close to harsh [4]. However, under the existing construction conditions, all construction teams lack the technology and method of inclination measurement while drilling, which is very 
disadvantageous to the quality of the hole body. Therefore, it is of great significance to research and develop measurement while drilling technology suitable for in-situ leaching drilling.

\section{Research status of inclined drilling equipment}

The research and development of MWD technology began in the early 1930s, which is to solve some difficult problems encountered in the drilling process in the oil industry and other drilling industries. In the early 1990s, wireless MWD technology developed and matured abroad [5-6]. At the end of 1990's, the research of wireless measurement while drilling technology was also carried out in China, and great economic benefits were obtained.

Wireless measurement while drilling has three different transmission systems: electromagnetic emission, acoustic wave and drilling hydraulic pressure pulse. The pressure pulse signal transmission system has the lowest operating cost and is easy to operate. Its advantage is that it does not need cables to transmit data, do not need to go back and forth, under the cables, save time, the whole inclination measurement process only needs about 5 minutes, while ensuring high-speed, convenient measurement of well deviation, but also avoids downhole accidents caused by cumbersome operation.

\section{Principle and technical parameters of wireless measurement while drilling}

\subsection{Working Principle}

The downhole inclinometer measures the azimuth angle and other information of well deviation. The downhole control actuator transmits the information of well deviation (the number of pulses) to the pulse generator. The device transmits the pulse signal to the surface device in the form of pressure pulse through drilling fluid. The surface electronic recorder records it and transmits it by the pressure sensor. Pulse signals are transmitted, so that drilling technicians can intuitively read out deviation data.

\subsection{Technical parameters}

a. Exploratory Tube Short Node Parameters

$\begin{array}{lr}\text { Inclination angle } & 0 \sim 180^{\circ} \quad \pm 0.1^{\circ} \\ \text { Azimuth } & 0 \sim 360^{\circ} \quad \pm 1.0^{\circ} \\ \begin{array}{l}\text { Performance index } \\ \text { Single battery working time }\end{array} & 200 \mathrm{~h} \\ \begin{array}{l}\text { Mud discharge } \\ \text { mud pressure }\end{array} & 10 \sim 55 \mathrm{~L} / \mathrm{s} \\ \text { Mud containing sand } & >3 \mathrm{Mpa} \\ \text { Mud density } & \leq 1 \%\end{array}$

\section{On-site shallow hole test}

Shallow hole test chooses $8 \#$ borehole for in-situ leaching uranium mining in a deposit in Xinjiang as test hole, designs $740 \mathrm{~m}$ depth of well, and drops inclinometer to $50 \mathrm{~m}$ depth of well, and starts shallow layer test. At the beginning of shallow test, the surface instrument did not receive any waveform pulse signal. After 20 minutes of continuous pumping and circulating mud drilling fluid, there was no pulse signal. It was speculated that the debonding of the instrument or the small and unstable displacement of the mud pump might be the cause. Drilling check whether the instrument is unlocked, after inspection, the instrument has good keying.

In the second test, the pressure of the mud pump is almost zero, and it is inferred that the pressure of the shallow mud pump may not reach. Continue to descend to $300 \mathrm{~m}$, receive extremely weak waveform, and data disorder, serious clutter, no inclinometer data appear. At this time, the pump pressure of the mud pump is less than $0.5 \mathrm{Mpa}$, which is far less than the rated technical parameter $3 \mathrm{Mpa}$. The measured displacement of the mud pump is $6 \mathrm{~L} / \mathrm{s}$, which is less than the rated displacement of the instrument, and the shallow test fails. 
Once again, the wireless measurement while drilling was removed, and it was found that the large piston of the pulse generator had been blocked by sediment (Fig. 1), which made the pulse generator unable to receive the mud signal, thus leading to the failure of the test.

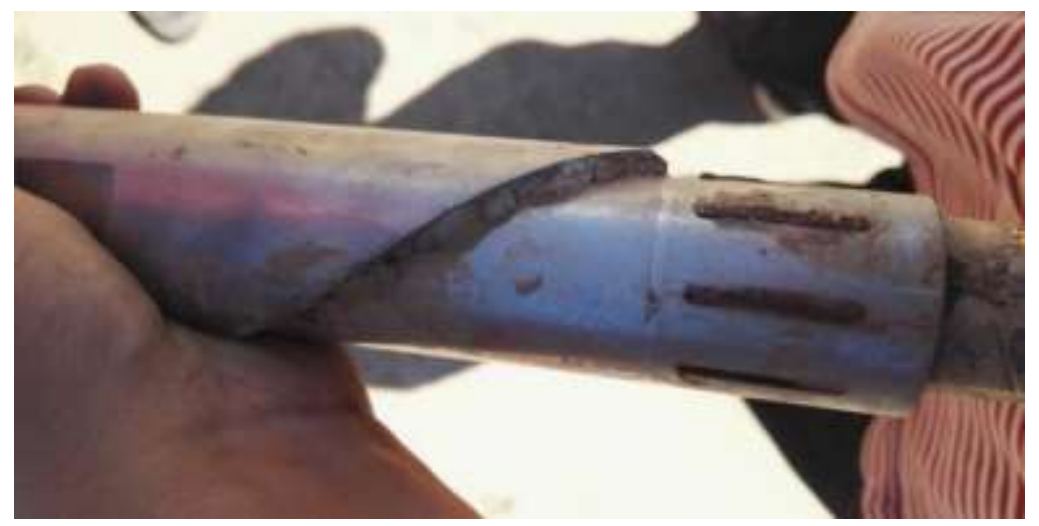

Fig. 1: Piston parts blocked by sediment.

\section{Test of Solid Content of Mud Drilling Fluids \\ 5.1. Collection of Mud Drilling Fluid Samples}

The mud drilling fluid samples were taken from the site of in-situ leaching test drilling in a deposit in Xinjiang (Fig. 2). The test samples are mud samples after sand removal by vibrating screen, numbered NJ-1 and NJ-2.

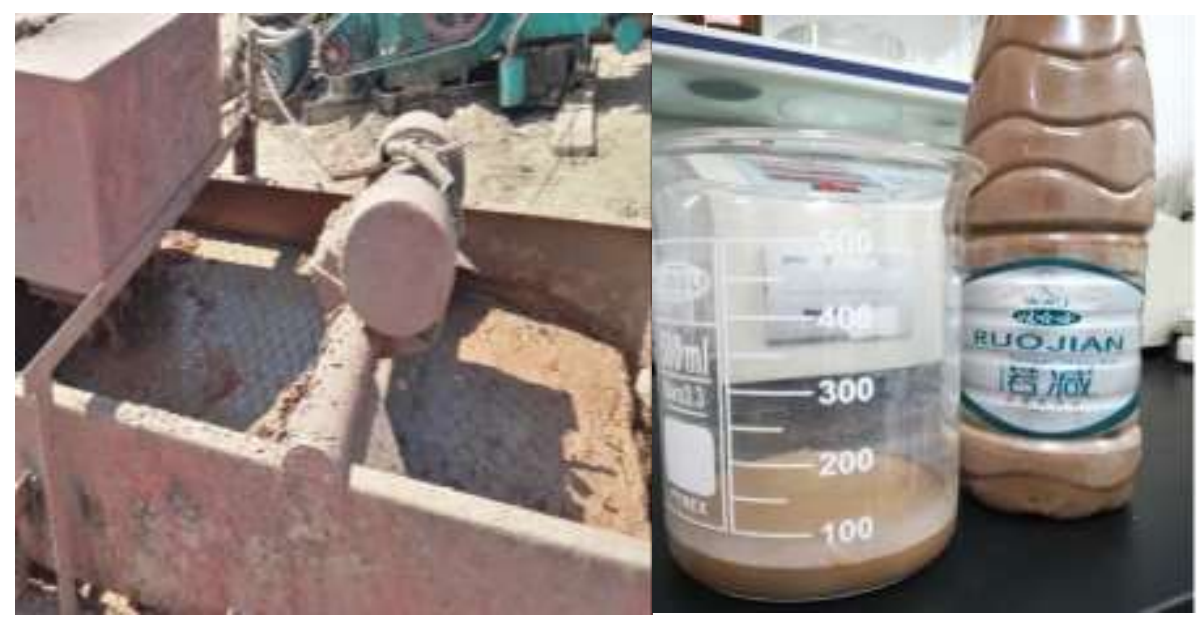

Fig. 2: Vibration desander for in-situ leaching construction site.

\subsection{Sand content test of mud drilling fluid}

The slurry sample was diluted and added a little flocculant. After precipitation for a moment, the solid particles settled down and the liquid phase gradually cleared. The density of raw materials was tested. The test results show that the density is $1.24 \mathrm{~g} / \mathrm{cm}^{3}$, the sand content is $16 \%$, and the water content is $84 \%$. The working parameters of wireless measurement while drilling require that the sand content of drilling fluid is less than $1 \%$. The sand content of mud drilling fluid after in-situ immersion drilling is far more than its working parameters, which results in blockage of large piston parts. 。 


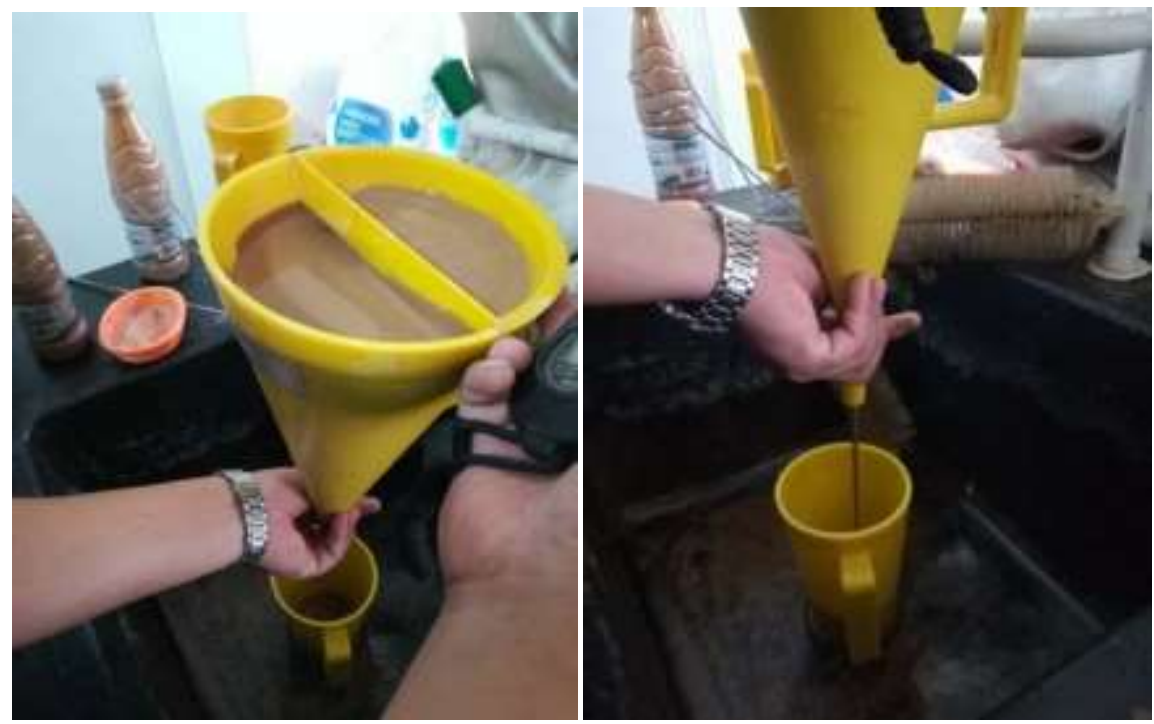

Fig. 3: Laboratory Mud Drilling Fluid Test.

\subsection{Discussion and Analysis of Existing Problems}

Wireless measurement while drilling is first used in in-situ leaching uranium drilling construction. Compared with oil industry, in-situ leaching uranium has great differences in drilling depth, drilling tool assembly, bit water hole diameter, drilling fluid type and solid content, mud discharge, mud pump type and so on. Therefore, it is necessary to consider all relevant factors comprehensively, discuss, analyze and summarize the main reasons for the failure of this test, and master the working mechanism of wireless measurement while drilling. According to the discussion and analysis, there are four aspects to be solved urgently:

The high solid content of mud drilling fluid after vibrating screen desander results in the blockage of large piston parts by sediment, which is the direct reason for the failure of the test. Secondary solid control equipment is added according to the need of the test.

\section{Deep hole application test of wireless measurement while drilling technology}

An in-situ leaching uranium test borehole 4 \# in a deposit in Xinjiang is designed with a depth of $740 \mathrm{M}$. The inclinometer begins to measure borehole trajectory at $230 \mathrm{~m}$ depth, subtracting the length of the exploration pipe to the drill bit from the depth of the well, that is, the actual depth of the tool subtracts $10 \mathrm{~m}$ from the depth of the well. The specific inclinometer data are shown in Table 2. In this test, more than 100 sets of effective deviation data are obtained by logging monitoring every 9 m drilling.

When drilling to $702 \mathrm{~m}$, the tool stops working, the deviation is 0.21 degree and the horizontal displacement is $1.29 \mathrm{~m}$ to the west, which fully meets the design requirements and guarantees the quality of the wellbore. The well deviation of geophysical survey after completion is $1.21 \mathrm{~m}$ at $700 \mathrm{~m}$ depth, which is basically consistent with the inclinometer.

In the process of drilling 4\# test hole in a deposit in Xinjiang, the deviation angle is always controlled in the range of 1 and compared with other mines with a depth of more than $600 \mathrm{~m}$ and production holes constructed with conventional inclinometer technology, the final hole deviation of $4 \#$ test hole is smaller, the inclinometer speed is faster, the number of times of drilling and pulling out of the well team is reduced, the labor intensity of the staff is reduced, and the survey is saved. The oblique assistant time is about 900 minutes. 


\section{Conclusion}

(1) Wireless measurement while drilling technology effectively solves the problem of in-situ leaching ultra-deep drilling in Xinjiang. The application of this technology shortens the time of deviation measurement, accurately grasps well trajectory, improves drilling efficiency, and organically combines deviation control with cost control.

(2) Wireless measurement while drilling is sensitive to the performance of mud drilling fluid. It is suggested that drill pipe filter be used to ensure the normal operation of the instrument. At the same time, it is suggested that mud drilling fluid be closed and circulated to reduce the interference of external environment.

\section{References}

[1] Jiang Yan, Hu Boshi, Tan Yahui, et al. "Construction Technology of Borehole Filter for in-situ Leaching of Multilayer Ore Body," J. Uranium Mining and Metallurgy, vol. 33, no. 2, pp. 185-191, 2014.

[2] Qin Hao, Hu Boshi, Zhang Yong, et al. "Application of Several Schedule Control Methods in Drilling Engineering of In-situ Leaching Uranium Mine,” J. Uranium Mining and Metallurgy, vol. 34, no. 4, pp. 245-248, 2015.

[3] Wang Xiwen, "Principle and Method for Determining the Optimum Spacing of in-situ Leaching Boreholes," J. Uranium Mining and Metallurgy, vol. 2, pp. 73-84, 1999.

[4] Li Xiaojian, Zhang Yong, Peng Fangqi et al. "Quality Control of Boring Construction Supervision for In-situ Leaching of Uranium in a Uranium Mine," J. Uranium Mining and Metallurgy, vol. 33, no. 3, pp. 162-165, 2014.

[5] Cai Wenjun, "Research on mechanical wireless measurement while drilling system," D. Beijing: China University of Petroleum, pp. 1-117, 2006. 